\title{
Analisis Kualitas Pembelajaran Guru Matematika dengan Menggunakan Model EKOP di SMK Teknologi Tri Tunggal '45 Makassar
}

\author{
Sumardin Raupu \\ Tadris Matematika, FTIK, Institut Agama Islam Negeri (IAIN) Palopo \\ Jl. Agatis, Kel. Balandai, Kota Palopo, Sulawesi Selatan, Indonesia \\ E-mail:aldhycool72@yahoo.co.id
}

\begin{abstract}
This research is a descriptive study that aimed to describe the quality of learning mathematics teacher at SMK Technology Tri Tunggal " 45 " based on the Model EKOP Makassar. Model EKOP is one Evaluation Model Learning Program, which not only assess the results (outputs) of learning, but also assesses the learning process carried out by the teacher. The instrument used in this study was a questionnaire given to teachers and students in mathematics teaching by the math teacher. The subjects were all teachers of mathematics in Technological Trinity "45". Analysis of the data used is the average of each component looks for good learning process and learning output, then compares to the quality standards that have been set. The results showed that (1) the quality of the learning process of mathematics teachers in the name of AMRN measured using Model EKOP is Good. (2) The quality of the learning process of mathematics teachers in the name JMT measured using Model EKOP is Good. (3) The output quality of learning mathematics teacher on behalf AMRN measured using Model EKOP is Good. (4) The output quality of learning mathematics teacher on behalf of JMT measured using Model EKOP is Moderate. (5) The quality of mathematics teacher learning program on behalf AMRN measured using Model EKOP are Good. (6) The quality of the learning program for mathematics teachers in the name JMT measured using Model EKOP is Moderate
\end{abstract}

Keywords: Quality of Learning, Math Teacher, EKOP.

\begin{abstract}
Abstrak
Jenis penelitian ini adalah penelitian deskriptif yang bertujuan untuk mendeskripsikan kualitas pembelajaran yang dilakukan oleh guru matematika di SMK Teknologi Tri Tunggal "45" Makassar yang diukur dengan menggunakan Model EKOP. Model EKOP merupakan salah satu Model Evaluasi Program Pembelajaran yang bukan hanya menilai hasil (output) pembelajaran tetapi juga menilai proses pembelajaran yang dilakukan oleh guru. Instrumen yang digunakan dalam penelitian ini adalah berupa angket yang diberikan kepada guru matematika dan siswa yang di ajar oleh guru matematika bersangkutan. Subjek penelitian ini adalah semua guru matematika yang ada di SMK Teknologi Tri Tunggal "45". Analisis data yang digunakan dengan mencari rerata setiap komponen pembelajaran baik proses maupun output pembelajaran kemudian membandingkan dengan standar kualitas yang telah ditetapkan. Hasil penelitian menunjukkan bahwa (1) kualitas proses pembelajaran guru matematika atas nama AMRN yang diukur dengan menggunakan Model EKOP berada dalam kategori Baik. (2) kualitas proses pembelajaran guru matematika atas nama JMT yang diukur dengan menggunakan Model EKOP berada dalam kategori Baik. (3) kualitas output pembelajaran guru matematika atas nama AMRN yang diukur dengan menggunakan Model EKOP berada dalam kategori Baik. (4) kualitas output pembelajaran guru matematika atas nama JMT yang diukur dengan menggunakan Model EKOP berada dalam kategori Cukup. (5) kualitas program pembelajaran guru matematika atas nama AMRN yang diukur dengan
\end{abstract}


menggunakan Model EKOP berada dalam kategori Baik. (6) kualitas program pembelajaran guru matematika atas nama JMT yang diukur dengan menggunakan Model EKOP berada dalam kategori Cukup.

Kata Kunci: Kualitas Pembelajaran, Guru Matematika, Model EKOP.

\section{Pendahuluan}

Indonesia yang selama ini dianggap sebagai negara berkembang, jika diukur dengan negara lain, maka posisinya jauh dari negara maju baik dari segi sumber daya manusia maupun dari kualitas pembelajaran. Keadaan Sumber Daya Manusia kita sangat tidak kompetitif. Untuk itu, perlu dilakukan pembaruan dan pembenahan dalam dunia pendidikan, dan yang memegang peranan penting dalam hal ini adalah guru.

Guru yang berkualitas adalah guru yang mampu mentransfer ilmu kepada peserta didiknya sehingga peserta didik mampu memahami materi yang diajarkan olehnya. Salah satu cara untuk mengetahui kualitas proses dan hasil pembelajaran peserta didik adalah dengan di adakannya evaluasi terhadap proses dan hasil pembelajaran guru bersangkutan. Salah satu model evaluasi yang dapat digunakan dalam menilai kualitas proses dan hasil pembelajran seorang guru adalah dengan menggunakan model EKOP.

Model EKOP adalah salah satu bentuk evaluasi yang menggunakan pendekatan penilaian proses dan hasil. Penilaian proses dalam hal ini disebut dengan penilaian kualitas hasil pembelajaran, sedangkan penilaian kualitas hasil pembelajaran disebut penilaian output pembelajaran, sehingga nama Model ini disebut dengan Model Evaluasi Kualitas Proses dan Output pembelajaran (Model EKOP).

Evaluasi model EKOP disusun berdasarkan kerangka pikir bahwa untuk mengevaluasi keberhasilan program pembelajaran, khususnya matematika ditingkat SMA/SMK tidak cukup hanya dengan menilai output belajar siswa semata, namun perlu menilai proses implementasi program dalam kelas, yang dalm penelitian ini disebut dengan kualitas pembelajaran. Hal ini perlu dilakukan karena bagaimanapun juga dalam setiap program kegiatan, output program selalu dipengaruhi oleh proses kegiatan itu sendiri, begiti juga dalam program pembelajaran. 
Penelitian mengenai kualitas Pembelajaran guru matematika dengan menggunakan Model EKOP, belum pernah dilakukan sama sekali di daerah Indonesia Bagian Tengah terkhusus dalam pelajaran matematika. Penelitian yang sama hanya pernah dilakukan di daerah Yogyakarta, itupun pada mata pelajaran IPS, sehingga perlu adanya penelitian untuk mengetahui bagaimana kualitas pembelajaran Guru Matematika ditinjau dari proses dan hasil belajar siswa dikelas yang diukur dengan menggunakan Model EKOP di daerah Indonesia Bagian Tengah khususnya Makassar. Hal inilah yang melatar belakangi penulis mengangkat judul tesis "Analisis Kualitas Pembelajaran Guru Matematika dengan di SMK Teknologi Tri Tunggal '45' Makassar".

\section{Kerangka Teoretis}

\section{Kualitas Proses dan Hasil Pembelajaran Matematika}

Surya menyatakan bahwa belajar dapat diartikan sebagai suatu proses yang dilakukan oleh individu untuk memperoleh perubahan perilaku baru secara keseluruhan, sebagai hasil dari pengalaman individu itu sendiri dalam berinteraksi dengan lingkungannya. ${ }^{1}$

Sedangkan Schoenfeld mendefinisikan bahwa belajar matematika berkaitan dengan apa dan bagaimana menggunakannya dalam membuat keputusan untuk memecahkan masalah ${ }^{2}$. Matematika melibatkan pengamatan, penyelidikan, dan keterkaitannya dengan fenomena fisik dan sosial.

Adapun pembelajaran adalah proses sengaja mengubah perilaku (to change behaviors) siswa sesuai dengan tujuan dan perencanaan pengajaran.. Pengajaran adalah usaha yang memberi kesempatan agar proses belajar dapat terjadi ketika pribadi bersentuhan dengan lingkungan maka pembelajaran terhadap siswa tidak hanya dilakukan di sekolah, sebab dunia adalah lingkungan belajar yang memungkinkan perubahan perilaku.

\footnotetext{
${ }^{1}$ Dewi Kurniawan Rusman, Pembelajaran Berbasis Teknologi Informatika Dan Komunikasi (Jakarta: Rajawali Press, 2011), 7.

2 Hamzah B Uno, Mengelola Kecerdasan Dalam Pembelajaran (Jakarta: Bumi Aksara, 2009), 110.
} 
Menurut Kamus Besar Bahasa Indonesia pengertian Kualitas adalah tingkat baik buruk sesuatu. Kualitas diartikan juga sebagai mutu, tingkat atau nilai sedangkan pembelajaran merupakan upaya penataan lingkungan yang memberi nuansa agar proses belajar tumbuh, berkembang dan terlaksana secara optimal ${ }^{3}$.

Proses adalah kegiatan yang dilakukan oleh siswa dalam mencapai tujuan pengajaran ${ }^{4}$. Dalam melakukan kegiatan belajar, terjadi proses berpikir yang melibatkan kegiatan mental. Dalam kegiatan mental, terjadi penyusunan hubungan informasi-informasi yang diterima sehingga timbul suatu pemahaman dan penguasaan materi yang diberikan. Pemahaman dan penguasaan ini disebut sebagai hasil belajar. Pembelajaran adalah proses interaksi peserta didik dengan guru dan sumber belajar pada suatu lingkungan belajar. Proses pembelajaran perlu direncanakan, dilaksanakan, dinilai, dan diawasi agar terlaksana secara efektif dan efisien.

Kualitas pembelajaran matematika dapat dilihat dalam dua segi yaitu kualitas proses dan kualitas hasil. Dari segi kualitas proses dapat dilihat aktifitas siswa dalam pembelajaran. Dari segi kualitas hasil dapat dilihat dari hasil belajar yang dicapai siswa. Pada kualitas pembelajaran matematika juga bermakna mutu proses dan produk pembelajaran matematika sebagai upaya penataan lingkungan yang memberi nuansa agar program belajar tumbuh dan berkembang secara optimal.

Adapun Purwanto mengemukakan bahwa hasil belajar merupakan perubahan perilaku akibat proses pendidikan sesuai dengan tujuan pendidikan ${ }^{5}$. Hasil belajar merupakan pencapaian tujuan pendidikan pada siswa yang mengikuti proses belajar mengajar.

Berdasarkan uraian tersebut di atas, dapat disimpulkan kualitas pembelajaran matematika dapat diartikan sebagai mutu, tingkat atau nilai, yang meliputi kualitas proses sebagai upaya pembelajar menciptakan nuansa yang mendukung agar proses belajar tumbuh, berkembang dan terlaksana secara optimal, sedangkan kualitas hasil belajar siswa terhadap materi pelajaran, kualitas hasil pembelajaran matematika adalah mutu yang ditandai dengan suatu nilai yang menunjukkan hasil dalam belajar matematika yang dicapai menurut kemampuan siswa dalam mengerjakan suatu tugas, indikatornya adalah keberhasilan yang telah ditetapkan dalam kurikulum

${ }^{3}$ Eko Putro Widoyoko, Kamus Besar Bahasa Indonesia, 4th ed. (Jakarta: PT. Gramedia Pustaka Utama, 2008), 744.

${ }^{4}$ Nana Sudjana, Penilaian Hasil Proses Belajar Mengajar (Bandung: PT. Remaja Rosdakarya, 2008), 22.

5 Purwanto, Evaluasi Hasil Belajar (Yogyakarta: Pustaka Pelajar, 2011), 23. 
KTSP yang disebut dengan Kriteria Ketuntasan Minimal (KKM) dan diukur dengan tes atau ketuntasan belajar siswa.

\section{Evaluasi Program Pembelajaran}

Evaluasi program pembelajaran merupakan suatu proses yang sistematis dan berkelanjutan untuk mengumpulkan, mendeskripsikan, menginterpretasikan, dan menyajikan informasi tentang implementasi rancangan program pembelajaran yang telah disusun oleh guru untuk dapat digunakan sebagai dasar membuat keputusan, menyusun kebijakan maupun menyusun program pembelajaran selanjutnya ${ }^{6}$.

Evaluasi program pembelajaran dilakukan dengan suatu maksud atau tujuan, antara lain: mengkomunikasikan program kepada publik, menyediakan informasi bagi pembuat keputusan, penyempurnaan program yang ada dan meningkatkan partisipasi. Adapun objek program pembelajaran mengacu pada asumsi bahwa pembelajaran merupakan sistem yang terdiri atas beberapa unsur, yaitu masukan, proses dan keluaran/hasil; maka objek atau sasaran evaluasi program pembelajaran dapat dibedakan menjadi tiga, yaitu : evaluasi masukan, proses dan keluaran/hasil pembelajaran.

Arikunto mengemukakan empat kemungkinan kebijakan yang dapat dilakukan berdasarkan hasil evaluasi pelaksanaan program, yaitu: (1) Menghentikan Program, (2) Merevisi Program, (3) Melanjutkan Program dan (4) Menyebarkan Program ${ }^{7}$.

${ }^{6}$ Eko Putro Widoyoko, Evaluasi Program Pembelajaran (Yogyakarta: Pustaka Pelajar, 2009), 10.

${ }^{7}$ Suharsimi Arikunto, Prinsip-Prinsip Dan Teknik Evaluasi Pengajaran (Bandung: PT. Remaja Rosdakarya, 2000), 22.

Al-Khwarizmi - 93 
Evaluasi Proses Pembelajaran

Sasaran evaluasi proses pembelajaran adalah pelaksanaan dan pengelolaan pembelajaran untuk memperoleh pemahaman tentang kinerja guru selama dalam pembelajaran, media pembelajaran yang digunakan oleh guru dalam pembelajaran, serta minat, sikap dan motivasi belajar siswa.

Adapun tahapan pelaksanaan evaluasi proses pembelajaran adalah sebagai berikut: menentukan tujuan, menentukan desain evaluasi, penyusunan instrumen penilaian, pengumpulan data, analisis dan interpretasi serta tindak lanjut

\section{Evaluator Program Pembelajaran}

Arikunto mengklasifikasikan evaluator menjadi dua macam, yaitu evaluator dari dalam (internal evaluator) dan evaluator dari luar (eksternal evaluator) ${ }^{8}$. Ebvaluator internal petugas evaluasi yang sekaligus merupakan salah seorang dari petugas atau anggota pelaksana program sementara evaluator eksternal berarti orang di luar pelaksana program tetapi orang yang terkait dengan kebijakan dan implementasi program.

Seorang evaluator harus mampu melaksanakan evaluasi berdasarkan teori dan keterampilan yang dimiliki, cermat dalam melihat program yang dievaluasi, objektif, sabar dan tekun, serta hati-hati dan bertanggung jawab. Semuanya penting untuk dimiliki seorang evaluator agar hasil evaluasi yang diperoleh dapat diterima oleh semua pihak.

\section{Model-Model Evaluasi Program}

Adapun Model-Model Evaluasi Program Pembelajaran diantaranya yaitu: Evaluasi Model Kirkpatrick, Evaluasi Model CIPP, Evaluasi Model Wheel (Roda), Evaluasi Model Provus (Discrepancy Model), Evaluasi model Stake (Countenance Model) dan Model EKOP.

${ }^{8}$ Suharsimi Arikunto, Prosedur Penelitian Suatu Pendekatan Praktik (Jakarta: Rineka Cipta, 2007), 23-25. 
Model Evaluasi Kualitas dan Output Pembelajaran (EKOP) menggunakan pendekatan evaluasi proses dan hasil. Evaluasi proses pembelajaran dalam hal ini disebut dengan evaluasi kualitas pembelajaran. Penilaian hasil pembelajaran dibatasi penilaian output pembelajaran, sehingga nama model ini disebut dengan model evaluasi kualitas dan output pembelajaran (model EKOP) ${ }^{9}$.

\section{Model EKOP}

Model ini disebut dengan Model Evaluasi Kualitas Proses dan Output pembelajaran, disingkat Model EKOP. Kualitas pembelajaran meliputi aspek: kinerja guru dalam kelas, fasilitas pembelajaran, iklim kelas, sikap dan motivasi belajar siswa. Output pembelajaran meliputi penilaian terhadap kecakapan akademik, kecakapan personal dan kecakapan sosial. Komponenkompenen tersebut dapat diwujudkan dalam bentuk bagan seperti yang terlihat pada Gambar 1 sebagai berikut: ${ }^{10}$

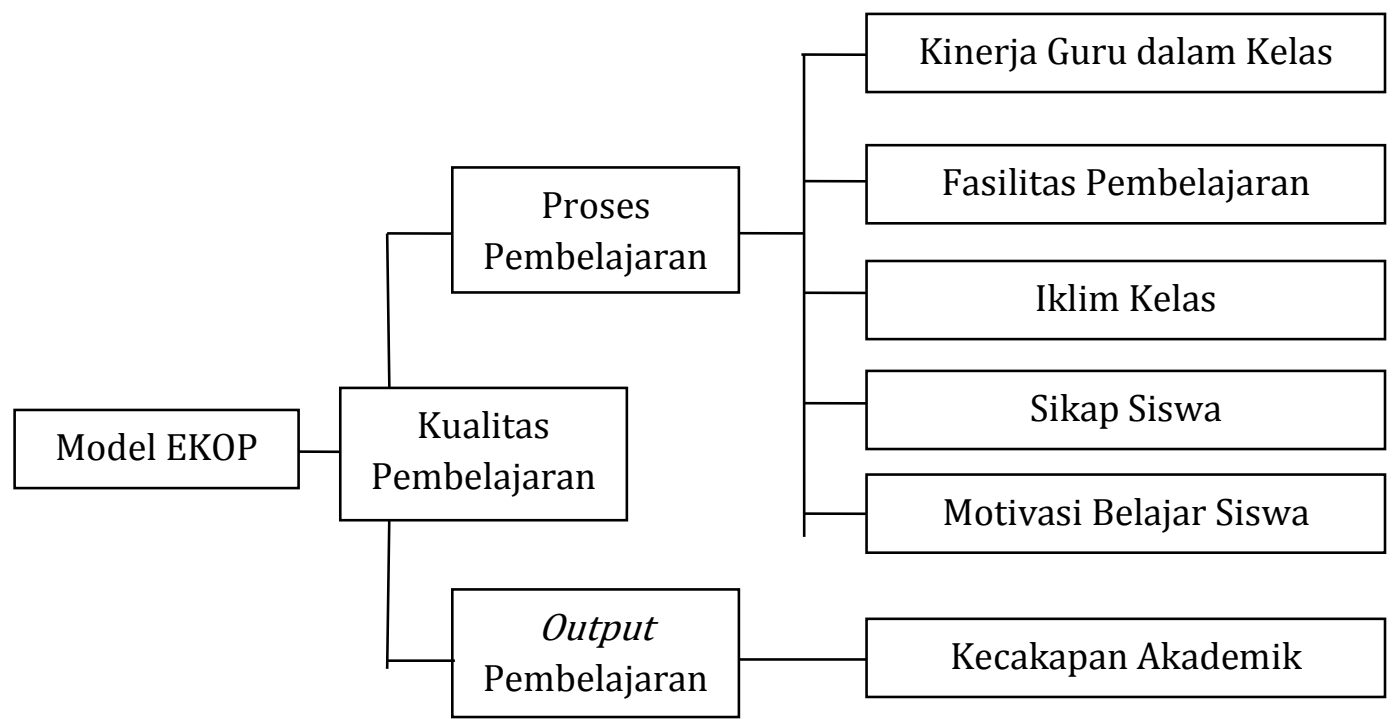

Gambar 1. Komponen Model EKOP

${ }^{9}$ S Eko Putro Widyoko, "Pengembangan Model Evaluasi Program Pembelajaran IPS Di SMP,” Penelitian Hibah Bersaing Ditjen DIkti Tahun 2007-2008, (n.d.), 3, http://www.umpwr.ac.id/download/publikasi-

ilmiah/Pengembangan\%20Model\%20Evaluasi\%20Program\%20Pembelajaran\%20IPS\%20d i\%20SMP.pdf.

10 Ibid. 


\section{Metode Penelitian}

Jenis penelitian ini adalah penelitian deskriptif. Penelitian ini dilaksanakan di SMK Teknologi Tri Tunggal "45" Makassar pada Semester Genap Tahun Pelajaran 2012/2013 dan subjek dalam penelitian ini adalah siswa kelas X MO 1 berjumlah 21 orang. dan kelas X TKJ 1 berjumlah 25 orang.

Adapun teknik pengumpulan data dalam penelitian ini adalah:

1. Guru menyusun rencana program pembelajaran secara lengkap yang akan dilaksanakan dikelas,

2. Melaksanakan program pembelajaran matematika sesuai dengan rancangan yang telah disusun sebelumnya,

3. Mempersiapkan instrumen untuk mengukur kualitas proses pembelajaran,

4. Memberikan instrumen penilaian kualitas proses pembelajaran kepada seluruh siswa pada sekitar 15 menit terakhir sebelum kegiatan pembelajaran berakhir pada pertemuan terakhir sebelum diadakan penilain hasil belajar siswa. Instrumen diisi dan dikumpulkan pada hari itu juga,

5. Memberikan instrumen penilaian kualitas proses pembelajaran kepada guru matematika yang akan dievaluasi program pembelajarannya,

6. Mengadakan penilaian terhadap output (kecakapan akademik) kegiatan pembelajaran yang telah dilaksanakan dengan menggunakan instrumen yang telah dipersiapkan,

7. Berdasarkan hasil penilaian terhadap kualitas proses dan output pembelajaran matematika kemudian diadakan evaluasi terhadap program pembelajaran yang telah dirancang dan dilaksanakan oleh guru,

8. Merumuskan rekomendasi kepada guru maupun sekolah berdasarkan hasil penilaian program pembelajaran.

\section{Analisis Kualitas Proses Pembelajaran}

Penilaian komponen kualitas proses pembelajaran melalui langkahlangkah sebagai berikut :

1. Menghitung nilai rerata skor tiap-tiap butir instrumen,

2. Menghitung nilai rerata skor total masing-masing komponen dan

3. Membandingkan nilai rerata total skor masing-masing komponen dengan kriteria seperti yang terlihat pada Tabel 1 berikut: 
Tabel 1. Kriteria Skor Butir

\begin{tabular}{|c|c|c|}
\hline Rumus & Rerata skor & Klasifikasi \\
\hline$X>\bar{X}_{l}+1,8 \times s b_{i}$ & $>4,2$ & Sangat Baik \\
\hline $\bar{X}_{l}+0,6 \times s b_{i}<X \leq \bar{X}_{l}+1,8 \times s b_{i}$ & $>3,4-4,2$ & Baik \\
\hline $\bar{X}_{l}-0,6 \times s b_{i}<X \leq \bar{X}_{l}+0,6 \times s b_{i}$ & $>2,6-3,4$ & Cukup \\
\hline $\bar{X}_{L}-1,8 \times s b_{i}<X \leq \bar{X}_{l}-0,6 \times s b_{i}$ & $>1,8-2,6$ & Kurang \\
\hline$X \leq \bar{X}_{l}-1,8 \times s b_{i}$ & $\leq 1,8$ & Sangat Kurang \\
\hline
\end{tabular}

(Sumber : Eko Putro, 2009:238) ${ }^{11}$

Keterangan :

$\bar{X}_{l}($ rerata ideal $)=1 / 2($ skor maks ideal - skor min ideal $)$

$\mathrm{Sb}_{\mathrm{i}}($ simpangan baku ideal $)=1 / 6$ (skor maks ideal - skor min ideal)

$\mathrm{X}=$ skor empiris

\section{Analisis Kualitas Output Pembelajaran}

Penilaian kualitas output pembelajaran matematika dilakukan dengan cara menghitung persentase skor kecakapan akademik kemudian dibandingkan dengan kriteria penilaian kualitas output pembelajaran yang dikeluarkan oleh Dinas Pendidikan sebagaimana yang terlihat pada Tabel 2 berikut :

Tabel 2. Kriteria Penilaiain Kualitas Output Pembelajaran

\begin{tabular}{|c|c|c|}
\hline Persentase Ketuntasan & Klasifikasi & Skor \\
\hline$>80$ & Sangat Baik & 5 \\
\hline$>60-80$ & Baik & 4 \\
\hline$>40-60$ & Cukup & 3 \\
\hline$>20-40$ & Kurang & 2 \\
\hline$\leq 20$ & Sangat Kurang & 1 \\
\hline
\end{tabular}

(Sumber : Dinas Pendidikan dalam Eko Putro, 2009:241) ${ }^{12}$

\section{Analisis Evaluasi Program Pembelajaran}

Evaluasi terhadap program pembelajaran matematika didasarkan rerata skor total 6 komponen (5 komponen kualitas proses pembelajaran dan 1 komponen kualitas output pembelajaran) kemudian dibandingkan standar evaluasi program pembelajaran matematika sebagaimana yang terlihat pada Tabel 3 berikut:

\footnotetext{
11 Widoyoko, Evaluasi Program Pembelajaran, 238.

12 Ibid., 241.
} 
Tabel 3. Standar Evaluasi Program Pembelajaran Matematika

\begin{tabular}{|c|c|}
\hline Rerata skor & Klasifikasi \\
\hline$>4,2$ & Sangat Baik \\
\hline$>3,4-4,2$ & Baik \\
\hline$>2,6-3,4$ & Cukup \\
\hline$>1,8-2,6$ & Kurang \\
\hline$\leq 1,8$ & Sangat Kurang \\
\hline
\end{tabular}

(Sumber : Eko Putro, 2009:243) ${ }^{13}$

\section{Pembahasan}

Analisis Komponen Kualitas Proses dan Output Pembelajaran Guru Matematika Kelas X TKJ 1

Tabel 4. Hasil Analisis Data Komponen Kualitas Proses Pemebelajaran Guru Kelas X TKJ 1

\begin{tabular}{|l|c|}
\hline \multicolumn{1}{|c|}{ Komponen Kualitas Proses Pembelajaran } & Rerata Skor \\
\hline Kinerja Guru Matematika & 3.95 \\
\hline Fasilitas Pembelajaran Matematika & 3.33 \\
\hline Iklim Kelas & 3.34 \\
\hline Sikap Siswa & 3.26 \\
\hline Motivasi Belajar Siswa & 3.87 \\
\hline \multicolumn{1}{|c|}{ Total } & 3.55 \\
\hline
\end{tabular}

Tabel 4 tersebut menunjukkan komponen kualitas proses pembelajaran guru matematika atas nama AMRN, guru matematika kelas X TKJ 1 yang terdiri dari lima komponen penilaian yaitu kinerja guru matematika, fasilitas pembelajaran matematika, iklim kelas, sikap siswa dan motivasi belajar siswa.

Jika kita mengacu pada rumus kriteria penilaian komponen, maka hanya komponen kinerja guru matematika dan motivasi belajar siswa yang masuk dalam kategori kualitas "baik". Tiga komponen yang lain yaitu iklim kelas, fasilitas pembelajaran matematika dan sikap siswa masuk dalam kategori kualitas " cukup". Namun jika dilihat secara keseluruhan, maka rerata skor untuk semua komponen kualitas proses pembelajaran guru matematika kelas X TKJ 1 atas nama AMRN masuk dalam kategori kualitas "baik" dengan rerata skor sebesar 3.55.

13 Ibid., 243. 
Analisis Kualitas Pembelajaran Guru Matematika ...

Analisis Komponen Kualitas Proses dan Output Pembelajaran Guru Matematika Kelas X MO 1

Tabel 5. Hasil Analisis Data Komponen Kualitas Proses Pembelajaran Guru Kelas X MO 1

\begin{tabular}{|l|c|}
\hline \multicolumn{1}{|c|}{ Komponen Kualitas Proses Pembelajaran } & Rerata Skor \\
\hline Kinerja Guru Matematika & 3.65 \\
\hline Fasilitas Pembelajaran Matematika & 3.30 \\
\hline Iklim Kelas & 3.14 \\
\hline Sikap Siswa & 3.37 \\
\hline Motivasi Belajar Siswa & 3.64 \\
\hline \multicolumn{1}{|c|}{ Total } & $\mathbf{3 . 4 2}$ \\
\hline
\end{tabular}

Tabel 5 tersebut menunjukkan komponen kualitas proses pembelajaran guru matematika atas nama JMT, guru matematika kelas X MO 1 yang terdiri dari lima komponen penilaian yaitu kinerja guru matematika, fasilitas pembelajaran matematika, iklim kelas, sikap siswa dan motivasi belajar siswa.

Jika kita mengacu pada rumus kriteria penilaian komponen yang terdapat, maka ada dua sub komponen yaitu kinerja guru matematika dan motivasi belajar siswa yang masuk dalam kategori kualitas "baik". Sub komponen yang lain yaitu iklim kelas, sikap dan fasilitas pembelajaran matematika masuk dalam kategori kualitas " cukup". Namun jika dilihat secara keseluruhan, maka rerata skor untuk semua komponen kualitas proses pembelajaran guru matematika kelas X MO 1 atas nama JMT masuk dalam kategori kualitas "baik" dengan rerata skor sebesar 3.42.

Analisis Komponen Kualitas Output Pembelajaran Guru Matematika Kelas X TKJ 1

Tabel 6. Hasil Analisis Data Persentase Ketuntasan Hasil Belajar Kelas X TKJ 1

\begin{tabular}{|c|c|c|c|}
\hline Persentase Skor & Kategori & Frekuensi & Persentase (\%) \\
\hline $0-70.3$ & Tidak Tuntas & 9 & 36 \\
\hline $70.4-100$ & Tuntas & 16 & 64 \\
\hline
\end{tabular}

Tabel 6 tersebut menunjukkan bahwa persentase ketuntasan hasil belajar matematika siswa kelas X TKJ 1 pada Semester Genap Tahun Pelajaran 2012/2013 sebesar $64 \%$, yaitu 16 dari 25 siswa termasuk dalam kategori tuntas dan $36 \%$ atau 9 orang dari 25 siswa termasuk dalam kategori tidak tuntas. Jadi terdapat 9 orang yang perlu diberikan perbaikan karena mereka belum mencapai kriteria ketuntasan individu. 
Hasil deskripsi ketuntasan tersebut kemudian dikonversi ke skala 5. Hasil konversi menunjukkan bahwa kualitas output pembelajaran matematika kelas X TKJ 1 oleh AMRN masuk dalam kualitas "baik" dengan skor 4.

Analisis Komponen Kualitas Output Pembelajaran Guru Matematika Kelas X MO 1

Tabel 7. Hasil Analisis Data Persentase Ketuntasan Hasil Belajar Kelas X MO 1

\begin{tabular}{|c|c|c|c|}
\hline $\begin{array}{c}\text { Persentase } \\
\text { Skor }\end{array}$ & Kategori & Frekuensi & Persentase (\%) \\
\hline $0-70.3$ & Tidak Tuntas & 10 & 47.62 \\
\hline $70.4-100$ & Tuntas & 11 & 52.38 \\
\hline
\end{tabular}

Tabel 7 tersebut menunjukkan bahwa persentase ketuntasan hasil belajar matematika siswa kelas X MO 1 pada Semester Genap Tahun Pelajaran 2012/2013 sebesar 52.38 \%, yaitu 11 dari 21 siswa termasuk dalam kategori tuntas dan $47.62 \%$ atau 10 orang dari 21 siswa termasuk dalam kategori tidak tuntas. Jadi terdapat 10 orang yang perlu diberikan perbaikan karena mereka belum mencapai kriteria ketuntasan individu.

Hasil deskripsi ketuntasan tersebut kemudian dikonversi ke skala 5. Hasil konversi menunjukkan bahwa kualitas output pembelajaran matematika kelas X MO 1 oleh JMT masuk dalam kualitas "cukup" dengan skor 3 .

Analisis Kualitas Proses dan Output Pembelajaran Guru Matematika Kelas X MO 1

Untuk skor kualitas proses dan output pembelajaran matematika diperoleh dengan cara mencari rerata antara skor total komponen kualitas proses dan skor total komponen kualitas output pembelajaran matematika sebagai berikut:

Skor rerata proses dan output pembelajaran $(\mathrm{S})=\frac{A+B}{2}$

Keterangan :

A $=$ Skor Total Komponen Proses Pembelajaran Matematika

B $=$ Skor Total Komponen Output Pembelajaran Matematika 
Untuk mendapatkan kualitas proses dan output pembelajaran matematika diperoleh dengan mengkonfirmasi rerata skor (S) dengan Standar Evaluasi Program Pembelajaran Matematika.

a. Kelas X TKJ 1 oleh AMRN

Hasilnya menunjukkan bahwa kualitas proses dan output pembelajaran matematika kelas X TKJ 1 oleh AMRN masuk dalam kategori "baik" dengan rerata skor 3.78 .

b. Kelas X MO 1 oleh JMT

Hasilnya menunjukkan bahwa kualitas proses dan output pembelajaran matematika kelas X MO 1 oleh JMT masuk dalam kategori "cukup" dengan rerata 3.21.

Data menunjukkan bahwa kualitas pembelajaran matematika oleh AMRN masuk dalam kategori "baik" dengan rerata 3.78 dan kualitas pembelajaran matematika oleh JMT masuk dalam kategori "cukup" dengan rerata 3.21. Secara keseluruhan kualitas pembelajaran matematika oleh AMRN lebih baik dari kualitas pembelajaran matematika oleh JMT, padahal jika kita melihat pada latar belakang pendidikan mereka, pengalaman mengajar guru matematika atas nama JMT jauh lebih lama dari guru matematika atas nama AMRN. Masa kerja guru matematika JMT dimulai dari tahun 2004 sedangkan AMRN sendiri dimulai pada tahun 2009. Dari penemuan ini kita dapat menarik kesimpulan bahwa pengalaman mengajar atau masa kerja yang lama bukan jaminan bahwa kualitas pembelajaran seorang guru akan baik.

Menindaklanjuti hasil penelitian, maka perlu diltelaah lebih jauh terhadap setiap komponen dan sub komponen kualitas pembelajaran matematika karena masih ada beberapa aspek yang perlu diperbaiki demi peningkatan kualitas pembelajaran matematika di masa akan datang

\section{Penutup}

Berdasarkan rumusan masalah, makaa dapat ditarik beberapa kesimpulan: (1)Kualitas proses pembelajaran guru matematika kelas X TKJ 1 atas nama AMRN yang di ukur dengan menggunakan model EKOP masuk dalam kategori kualitas "Baik", (2)Kualitas proses pembelajaran guru matematika kelas X MO 1 atas nama AMRN yang di ukur dengan menggunakan model EKOP masuk dalam kategori kualitas "Baik", (3)Kualitas output pembelajaran guru matematika kelas X TKJ1 atas nama AMRN yang di ukur dengan menggunakan model EKOP masuk dalam kategori kualitas "Baik", (4) Kualitas output pembelajaran guru matematika kelas X MO 1 atas nama JMT yang di ukur dengan menggunakan model EKOP masuk dalam kategori kualitas "Cukup", (5)Kualitas program pembelajaran guru matematika kelas X TKJ 1 atas nama AMRN yang di ukur dengan 
menggunakan model EKOP masuk dalam kategori kualitas "Baik", (6)Kualitas program pembelajaran guru matematika kelas X MO 1 atas nama JMT yang di ukur dengan menggunakan model EKOP masuk dalam kategori kualitas "Cukup".

\section{Daftar Pustaka}

Arikunto, Suharsimi. Prinsip-Prinsip Dan Teknik Evaluasi Pengajaran. Bandung: PT. Remaja Rosdakarya, 2000.

_-_. Prosedur Penelitian Suatu Pendekatan Praktik. Jakarta: Rineka Cipta, 2007.

Purwanto. Evaluasi Hasil Belajar. Yogyakarta: Pustaka Pelajar, 2011.

Rusman, Dewi Kurniawan. Pembelajaran Berbasis Teknologi Informatika Dan Komunikasi. Jakarta: Rajawali Press, 2011.

Sudjana, Nana. Penilaian Hasil Proses Belajar Mengajar. Bandung: PT. Remaja Rosdakarya, 2008.

Uno, Hamzah B. Mengelola Kecerdasan Dalam Pembelajaran. Jakarta: Bumi Aksara, 2009.

Widoyoko, Eko Putro. Evaluasi Program Pembelajaran. Yogyakarta: Pustaka Pelajar, 2009.

-_—. Kamus Besar Bahasa Indonesia. 4th ed. Jakarta: PT. Gramedia Pustaka Utama, 2008.

Widyoko, S Eko Putro. "Pengembangan Model Evaluasi Program Pembelajaran IPS Di SMP." Penelitian Hibah Bersaing Ditjen DIkti Tahun 2007-2008, n.d. http://www.umpwr.ac.id/download/publikasiilmiah/Pengembangan\%20Model\%20Evaluasi\%20Program\%20Pembe lajaran\%20IPS\%20di\%20SMP.pdf. 